\title{
Integrated Models of Care for People Living with Hepatitis C Virus and a Substance Use Disorder: Protocol for a Systematic Review
}

Lianping Ti ${ }^{1,2}, \mathrm{PhD}$; Stephanie Parent ${ }^{1}, \mathrm{MPH}$; María Eugenia Socías ${ }^{2,3}, \mathrm{MD}$

${ }_{1}^{1}$ British Columbia Centre for Excellence in HIV/AIDS, Vancouver, BC, Canada

${ }^{2}$ Department of Medicine, University of British Columbia, Vancouver, BC, Canada

${ }^{3}$ British Columbia Centre for Substance Use, Vancouver, BC, Canada

Corresponding Author:

Lianping Ti, PhD

British Columbia Centre for Excellence in HIV/AIDS

608-1081 Burrard Street

Vancouver, BC, V6Z 1Y6

Canada

Phone: 16046822344 ext 66885

Fax: 16048068464

Email: $\underline{\text { mintti@cfenet.ubc.ca }}$

\section{Abstract}

Background: People living with a substance use disorder (SUD) are a key population within the hepatitis C virus (HCV) epidemic. While integrated and community-based models of care have shown positive outcomes among this population, the literature has been primarily focused on the HIV context. This paper outlines a systematic review protocol on the impact of various integrated models of care, which includes HCV and SUD services, on various treatment, and health-related outcomes among this population.

Objective: The objective of this review is to determine the impact of integrated models of care on HCV and addiction treatment and health-related outcomes for adults living with HCV and an SUD.

Methods: We will search 5 databases, article reference lists, and abstracts from relevant conferences that investigate the impact of integrated models of care on treatment and health-related outcomes among people living with HCV and an SUD. Database searches will be conducted and titles, abstracts, and the full-text of the relevant studies will be independently reviewed in separate stages. The methodological quality of included studies will be assessed using a validated tool. Data from included articles will be extracted using a standardized form and synthesized in a narrative account.

Results: For this project, we have received funding from the Canadian Institute of Health Research. To date, we have completed the search strategy, reviewed the titles, abstracts, and full-texts. Grading the selected studies and qualitative synthesis of the results are currently under way, and we expect the final results to be submitted for publication in the fall of 2018.

Conclusions: The systematic review will describe different integrated models of care that could be effective in improving the health and well-being of people living with HCV and an SUD. Results of this review could also identify quality improvement strategies to minimize the health and cost burden imposed on patients, healthcare professionals, and the healthcare system.

Trial Registration: PROSPERO CRD42017078445; https://www.crd.york.ac.uk/prospero/display_record.php?RecordID=78445 (Archived by WebCite at http://www.webcitation.org/6z4YnkE9G)

(JMIR Res Protoc 2018;7(5):e122) doi: 10.2196/resprot.9532

\section{KEYWORDS}

hepatitis $\mathrm{C}$ virus; substance use disorder; integrated care; protocol; systematic review

\section{Introduction}

People living with a substance use disorder (SUD) are a key population within the hepatitis $\mathrm{C}$ virus (HCV) epidemic. Specifically, the estimated global HCV prevalence among people who inject drugs (PWID) is 67\%, or approximately 10 million individuals, with incidence rates ranging from $5 \%$ to $45 \%$ per year [1]. PWID constitute approximately $14 \%$ of the 71 million people infected with HCV globally [2]. Due to similar transmission routes, there is overrepresentation of PWID among 
individuals who are co-infected with HCV and HIV, with over half of the 2.3 million globally co-infected individuals being among PWID [3,4]. PWID are not only at greater risk of HCV infection (and re-infection), but also at increased risk of disease progression, mortality, and onward HCV transmission due to various socio-structural and environmental exposures, including poor access to health care services, socioeconomic marginalization, and the persistence of law enforcement-based responses to illicit drug use [1,5-7]. While $\mathrm{HCV}$ is mainly transmitted via injection drug use, non-injection drug use has also been associated with $\mathrm{HCV}$ infection. For example, there is some evidence of $\mathrm{HCV}$ transmission via crack pipe sharing [8], and among men who have sex with men who use non-intravenous drugs $[9,10]$. HCV prevalence is higher in non-injecting drug users than in nondrug users. Moreover, many PWID are polysubstance users with non-injection drugs [11].

Despite the advent of safe and highly efficacious direct-acting antiviral-based therapy, resulting in the possibility of controlling the HCV epidemic, concerns regarding treatment access, adherence, and potential reinfection, particularly among marginalized populations such as PWID, remain [5,6]. Indeed, access and uptake of HCV treatment has been consistently low among PWID, with studies indicating that only $1 \%-6 \%$ of this population has ever been treated with interferon-based therapies [12-14]. The reluctance of physicians to treat HCV infection in PWID is likely due to the stigma and discrimination that continue to persist among this population [15]. Low treatment rates among this population may also reflect PWIDs' fear of treatment, competing priorities (eg, active illicit drug use), as well as general barriers to accessing healthcare [16,17]. Moreover, in some jurisdictions, the high cost of direct-acting antivirals (DAA) treatment is only covered provided that the patient meets specific criteria (eg, a fibrosis score of 2 or more) [18]. As such, the high cost of DAA may also constitute a barrier to treatment for PWID who do not meet these criteria, or who live in settings where DAA treatment is not covered. Nevertheless, recent studies have shown that, when appropriately supported, PWID are able to achieve similar rates of sustained virologic response compared to the general population $[19,20]$.

Prior reviews have explored integrated models of care in the context of HIV, and these have been shown to have a significant beneficial impact on the treatment and health outcomes of PWID, particularly when coupled with SUD services [21]. Similarly, emerging studies have suggested the importance of opioid agonist therapy (OAT) and mental health services on reducing the risk of $\mathrm{HCV}$ reinfection among this population [19,22-24]. However, there has been no explicit systematic review conducted on the impact of $\mathrm{HCV}$ and SUD integrated programs and services on $\mathrm{HCV}$, and addiction treatment and health outcomes among individuals living with these comorbid diseases. This review will address an important gap in the literature by comprehensively assessing the available literature to provide insight into effective and efficient models of care for people living with HCV and SUD.

\section{Methods}

The current protocol has been registered in the PROSPERO CRD42017078445 and conforms to the Preferred Reporting Items for Systematic Reviews and Meta-Analyses Protocols (PRISMA-P) checklist (Multimedia Appendix 1). We will also adhere to the PRISMA guidelines for the development of this systematic review report [25].

\section{Research Question}

The proposed systematic review will synthesize the existing literature on HCV and SUD integrated models of care to date. Specifically, this review aims to answer the following research question: what is the impact of integrated models of care on $\mathrm{HCV}$ and addiction treatment outcomes (eg, HCV treatment adherence, OAT uptake), health-related outcomes (eg, HCV clearance), and cost-related outcomes (eg, long-term cost effectiveness) for adults living with HCV and an SUD?

\section{Eligibility}

Original quantitative and qualitative research studies that reported on integrated care models for adults living with HCV and an SUD will be included. For the present study, substance use will be defined as any use of alcohol, illicit use or misuse of opioids (eg, heroin, prescription opioids, methadone, morphine, oxycodone), or stimulants (eg, cocaine, methamphetamine). We will include studies that describe service integration interventions at varying degrees of integration. Some examples may include HCV screening or treatment within OAT clinics or multidisciplinary care addressing medical, psychological, social, and addiction-related needs.

Commentaries, letters to editors, editorials, and other types of opinion pieces will be excluded. Literature reviews will also be excluded; however, we will conduct back referencing to ensure that all relevant studies from the literature review are captured. The search will not be restricted to setting. Moreover, we will not exclude studies based on study design, but the degree of bias will be noted in interpreting the findings. The search will be restricted to publications in English, French, and Spanish.

\section{Information Sources and Search Strategy}

A comprehensive search strategy to identify documents that met the eligibility criteria will be conducted. Specifically, the databases MEDLINE, EMBASE, CINAHL, PsycINFO, and Web of Science will be searched with no date restrictions in order to acknowledge changes in care over time. However, we will ensure that the study period is included in our analysis. In addition, we will search ClinicalTrials.gov to ensure that we capture studies that have not yet been published. Consistent with similar reviews [21], search terms will include those that are related to three themes, namely $\mathrm{HCV}$, substance use, and integrated healthcare services, and these terms will be mapped to database-specific medical subject headings and controlled vocabulary terms when available (Multimedia Appendix 2).

To maximize the number of included studies, hand-searching of full-text scientific conference proceedings from HCV- and substance use conferences (eg, American Association for the Study of Liver Diseases, European Association for the Study 
of the Liver, Conference on Retroviruses and Opportunistic Infections, International AIDS Society Conference) will be conducted and will be restricted to be within the previous two years. We restricted the conference abstract search to the past two years in order to limit duplication with older abstracts that may have been published as academic articles. We will also search reference lists of research articles and reviews by hand to identify relevant articles not otherwise captured. These search methods have been developed in consultation with a medical reference librarian with expertise in systematic reviews and population and public health at the University of British Columbia (U. Ellis, personal communication, June 12, 2017) and will be executed by an author experienced in conducting systematic reviews.

\section{Study Records}

Database searches will be conducted and the abstracts and full-text articles from the search strategy will be imported into Endnote X7. After removing duplicates, the titles, abstracts, and full text of articles will be independently reviewed in three separate stages by two research team members. The first stage will consist of reviewing the titles. The second stage will consist of reviewing the abstracts. The third stage will be the review of the full text of the articles. At each review stage, studies clearly not meeting the inclusion criteria will be excluded from further review and the reason for exclusion will be recorded. Any disagreements between the two investigators will be resolved by discussion with a third investigator.

\section{Risk of Bias in Individual Studies}

The methodological quality, including risk of bias, of included quantitative research studies will be assessed using a modified version of the Downs and Black checklist for the reporting of healthcare studies, which has been shown to be a valid and reliable tool [26,27]. Higher scores out of a total score of 18 represent higher overall methodological quality. Qualitative studies will be assessed using the Critical Appraisal Skills Programme tool [28], a widely used tool recommended by some journals [29]. Each study will be scored by one investigator and verified independently by a second investigator. Where there were disagreements in scoring, this will be resolved by discussion with a third investigator.

\section{Data Synthesis}

Following PRISMA guidelines, a flow chart of the selection process will be produced. Additionally, data from included studies will be extracted using a standardized form developed to capture study characteristics and main findings and summarized in a table, including information on: study characteristics (eg, study setting, study design, study period, and study population), participant characteristics (eg, age, sex or gender), study objectives, integrated service intervention type and type of facility, and main study findings. Findings from the included studies will then be synthesized in a narrative account that addresses the objectives of this systematic review.

\section{Results}

We have received funding from the Canadian Institute of Health Research, allowing the commencement of the project. To date, we have completed the search strategy. We obtained 1711 records after duplicates were removed. After screening the titles and abstracts, 153 full-texts were reviewed. Of those, 57 were excluded and 96 will be included in the qualitative synthesis. After hand-searching conferences abstracts, 36 were selected for inclusion. We are currently in the process of grading the selected full-texts, and qualitative synthesis of the findings is currently under way. We expect the final results to be submitted for publication in the fall of 2018 .

\section{Discussion}

To our knowledge, this systematic review will be the first to synthesize the available evidence on the integration of $\mathrm{HCV}$ and substance use services on treatment, health, and cost-related outcomes. Identification and implementation or adaption of different integrated models of care to improve the health and well-being of people living with HCV and an SUD may have a significant impact on reducing the negative health and social consequences associated with these comorbid diseases, as well as healthcare utilization costs, and resource burden on the healthcare system. The results of this systematic review may guide future research in this area and contribute to the development of evidence-based policies and programs for the treatment and care of people living with HCV and an SUD.

We plan to implement a comprehensive end-of-project knowledge translation strategy to ensure that the findings of this research are accessible to key stakeholders. Specifically, we will present the results of this review at relevant HCV and substance use meetings nationally and internationally, as well as publish in an open access peer-reviewed journal in an effort to increase access for appropriate scientific, clinical, and public audiences. Lastly, we plan to collaborate with relevant clinical programs and community organizations to ensure the timely and effective application of the research findings. Specifically, we will organize plain language presentations of our research findings with time for discussion and feedback, we will attend meetings and planning discussions with health authorities and health administrators, and we will reach out to policy-makers via briefing notes or other venues.

There are several limitations that should be noted. The expected heterogeneity of the literature on integrated models of care may affect our ability to draw clear conclusions from the literature. Additionally, we recognize that the selection and qualitative synthesis of the eligible studies is a subjective process; however, we will seek to minimize this limitation by duplicating our search and utilizing two reviewers to conduct the screening and quality assessment processes independently. As with all reviews, it is possible that some eligible studies may be missed in our search strategy. To minimize this limitation, we have kept our search strategy relatively broad and have sought input from an experienced librarian. Lastly, there may be a publication bias observed as a general limitation of systematic reviews. We will try to minimize this issue by searching databases for unpublished studies (eg, ClinicalTrials.gov).

In sum, this systematic review will synthesize the available evidence on the integration of HCV and substance use services and its impact on various outcomes, including health- and 
cost-related outcomes. It is expected that the findings from this review will provide evidence towards the effective delivery of healthcare programs and services for people living with $\mathrm{HCV}$ and an SUD.

\section{Acknowledgments}

This project was funded by the Canadian Institutes of Health Research (CIHR) bridging grant (\#153431). LT is supported by a Michael Smith Foundation for Health Research (MSFHR) Scholar Award. MES is supported by a MSFHR Postdoctoral Fellowship Award and a CIHR Fellowship Award. The sponsors had no involvement in the review and approval of the manuscript for publication.

\section{Authors' Contributions}

LT and MES designed the systematic review protocol, with support of a health librarian. LT prepared the first draft. MES and SP reviewed and revised the first draft. All authors read and approved the final manuscript.

\section{Conflicts of Interest}

None declared.

\section{Multimedia Appendix 1}

Preferred Reporting Items for Systematic Reviews and Meta-Analyses Protocols (PRISMA-P) checklist.

[PDF File (Adobe PDF File), 116KB-Multimedia Appendix 1]

\section{Multimedia Appendix 2}

Search Strategy in OVID MEDLINE.

[PDF File (Adobe PDF File), 219KB-Multimedia Appendix 2]

\section{References}

1. Nelson PK, Mathers BM, Cowie B, Hagan H, Des JD, Horyniak D, et al. Global epidemiology of hepatitis B and hepatitis $\mathrm{C}$ in people who inject drugs: results of systematic reviews. Lancet 2011 Aug 13;378(9791):571-583 [FREE Full text] [doi: 10.1016/S0140-6736(11)61097-0] [Medline: 21802134]

2. World Health Organization. 2017. Hepatitis C URL: http://www.who.int/mediacentre/factsheets/fs164/en/ [accessed 2017-09-22] [WebCite Cache ID 6xWlwrwm5]

3. Platt L, Easterbrook P, Gower E, McDonald B, Sabin K, McGowan C, et al. Prevalence and burden of HCV co-infection in people living with HIV: a global systematic review and meta-analysis. Lancet Infect Dis 2016 Jul;16(7):797-808. [doi: 10.1016/S1473-3099(15)00485-5] [Medline: 26922272]

4. World Health Organization. 2017 Sep 22. People who inject drugs URL: http://www.who.int/hiv/topics/idu/en/ [accessed 2017-09-22] [WebCite Cache ID 6vLFNG0t9]

5. Backmund M, Meyer K, Von ZM, Eichenlaub D. Treatment of hepatitis C infection in injection drug users. Hepatology 2001 Jul;34(1):188-193. [doi: 10.1053/jhep.2001.25882] [Medline: 11431750 ]

6. Grady BP, Schinkel J, Thomas XV, Dalgard O. Hepatitis C virus reinfection following treatment among people who use drugs. Clin Infect Dis 2013 Aug;57 Suppl 2:S105-S110. [doi: 10.1093/cid/cit301] [Medline: 23884057]

7. Hagan H, Thiede H, Des JDC. Hepatitis C virus infection among injection drug users: survival analysis of time to seroconversion. Epidemiology 2004 Sep;15(5):543-549. [Medline: 15308953]

8. Macías J, Palacios RB, Claro E, Vargas J, Vergara S, Mira JA, et al. High prevalence of hepatitis C virus infection among noninjecting drug users: association with sharing the inhalation implements of crack. Liver Int 2008 Jul;28(6):781-786. [doi: 10.1111/j.1478-3231.2008.01688.x] [Medline: 18312289]

9. Götz HM, van DG, Niesters HG, den HJG, Thio HB, de ZO. A cluster of acute hepatitis C virus infection among men who have sex with men--results from contact tracing and public health implications. AIDS 2005 Jun 10;19(9):969-974. [Medline: 15905679]

10. Scheinmann R, Hagan H, Lelutiu-Weinberger C, Stern R, Des JDC, Flom PL, et al. Non-injection drug use and Hepatitis C Virus: a systematic review. Drug Alcohol Depend 2007 Jun 15;89(1):1-12 [FREE Full text] [doi: 10.1016/j.drugalcdep.2006.11.014] [Medline: 17174481]

11. Hayden A, Hayashi K, Dong H, Milloy M, Kerr T, Montaner JSG, et al. The impact of drug use patterns on mortality among polysubstance users in a Canadian setting: a prospective cohort study. BMC Public Health 2014 Nov 06;14:1153 [FREE Full text] [doi: 10.1186/1471-2458-14-1153] [Medline: 25377274] 
12. Mehta SH, Genberg BL, Astemborski J, Kavasery R, Kirk GD, Vlahov D, et al. Limited uptake of hepatitis C treatment among injection drug users. J Community Health 2008 Jun;33(3):126-133 [FREE Full text] [doi: 10.1007/s 10900-007-9083-3] [Medline: $\underline{18165889}$ ]

13. Iversen J, Grebely J, Topp L, Wand H, Dore G, Maher L. Uptake of hepatitis C treatment among people who inject drugs attending Needle and Syringe Programs in Australia, 1999-2011. J Viral Hepat 2014 Mar;21(3):198-207. [doi:

10.1111/jvh.12129] [Medline: 24438681]

14. Grebely J, Raffa JD, Lai C, Kerr T, Fischer B, Krajden M, et al. Impact of hepatitis C virus infection on all-cause and liver-related mortality in a large community-based cohort of inner city residents. J Viral Hepat 2011 Jan;18(1):32-41. [doi: 10.1111/j.1365-2893.2010.01279.x] [Medline: 20196806]

15. Habib SE, Adorjany LV. Hepatitis $\mathrm{C}$ and injecting drug use: The realities of stigmatisation and discrimination. Health Education Journal 2016 Jul 27;62(3):256-265. [doi: 10.1177/001789690306200307]

16. Edlin BR, Kresina TF, Raymond DB, Carden MR, Gourevitch MN, Rich JD, et al. Overcoming barriers to prevention, care, and treatment of hepatitis C in illicit drug users. Clin Infect Dis 2005 Apr 15;40 Suppl 5:S276-S285 [FREE Full text] [doi: 10.1086/427441] [Medline: 15768335]

17. Jones L, Atkinson A, Bates G, McCoy E, Porcellato L, Beynon C, et al. Views and experiences of hepatitis C testing and diagnosis among people who inject drugs: systematic review of qualitative research. Int J Drug Policy 2014

Mar;25(2):204-211. [doi: 10.1016/j.drugpo.2013.11.004] [Medline: 24332457]

18. British Columbia Ministry of Health. 2017. PharmaCare coverage of new direct-acting antiviral drugs and expanded coverage for adults with chronic hepatitis C infection URL: https://www2.gov.bc.ca/assets/gov/health/health-drug-coverage/pharmacare/ chc-new-daas-and-expandedcoverage.pdf [accessed 2018-02-20] [WebCite Cache ID 6xWmBfde0]

19. Dimova RB, Zeremski M, Jacobson IM, Hagan H, Des JDC, Talal AH. Determinants of hepatitis C virus treatment completion and efficacy in drug users assessed by meta-analysis. Clin Infect Dis 2013 Mar;56(6):806-816 [FREE Full text] [doi:

10.1093/cid/cis 1007] [Medline: 23223596]

20. Aspinall EJ, Corson S, Doyle JS, Grebely J, Hutchinson SJ, Dore GJ, et al. Treatment of hepatitis C virus infection among people who are actively injecting drugs: a systematic review and meta-analysis. Clin Infect Dis 2013 Aug;57 Suppl 2:S80-S89. [doi: $10.1093 / \mathrm{cid} / \mathrm{cit} 306]$ [Medline: 23884071]

21. Haldane V, Cervero-Liceras F, Chuah FL, Ong SE, Murphy G, Sigfrid L, et al. Integrating HIV and substance use services: a systematic review. J Int AIDS Soc 2017 Dec 30;20(1):21585 [FREE Full text] [doi: 10.7448/IAS.20.1.21585] [Medline: 28692211]

22. Perlman DC, Jordan AE, Uuskula A, Huong DT, Masson CL, Schackman BR, et al. An international perspective on using opioid substitution treatment to improve hepatitis $C$ prevention and care for people who inject drugs: Structural barriers and public health potential. Int J Drug Policy 2015 Nov;26(11):1056-1063 [FREE Full text] [doi: 10.1016/j.drugpo.2015.04.015] [Medline: 26050614]

23. Dore GJ, Altice F, Litwin AH, Dalgard O, Gane EJ, Shibolet O, C-EDGE CO-STAR Study Group. Elbasvir-Grazoprevir to Treat Hepatitis C Virus Infection in Persons Receiving Opioid Agonist Therapy: A Randomized Trial. Ann Intern Med 2016 Nov 01;165(9):625-634. [doi: 10.7326/M16-0816] [Medline: 27537841]

24. Platt L, Minozzi S, Reed J, Vickerman P, Hagan H, French C, et al. Needle syringe programmes and opioid substitution therapy for preventing hepatitis $C$ transmission in people who inject drugs. Cochrane Database Syst Rev 2017 Dec 18;9:CD012021 [FREE Full text] [doi: 10.1002/14651858.CD012021.pub2] [Medline: 28922449]

25. Moher D, Liberati A, Tetzlaff J, Altman DG. Preferred reporting items for systematic reviews and meta-analyses: the PRISMA statement. Int J Surg 2010;8(5):336-341 [FREE Full text] [doi: 10.1016/j.ijsu.2010.02.007] [Medline: 20171303]

26. Downs SH, Black N. The feasibility of creating a checklist for the assessment of the methodological quality both of randomised and non-randomised studies of health care interventions. J Epidemiol Community Health 1998 Jun;52(6):377-384 [FREE Full text] [Medline: 9764259]

27. Marshall BDL, Werb D. Health outcomes associated with methamphetamine use among young people: a systematic review. Addiction 2010 Jun;105(6):991-1002. [doi: 10.1111/j.1360-0443.2010.02932.x] [Medline: 20659059]

28. Critical Appraisal Skills Programme. CASP qualitative checklist URL: http://www.casp-uk.net/referencing [accessed 2018-02-28] [WebCite Cache ID 6xZiN4ezb]

29. Neale J, West R. Guidance for reporting qualitative manuscripts. Addiction 2015 Apr;110(4):549-550. [doi: 10.1111/add.12857] [Medline: 25771688]

\section{Abbreviations}

DAA: direct-acting antivirals

HCV: hepatitis C

OAT: opioid agonist therapy

PRISMA: Preferred Reporting Items for Systematic Reviews and Meta-Analyses Protocols

PRISMA: people who inject drugs

SUD: substance use disorder 
Edited by G Eysenbach; submitted 30.11.17; peer-reviewed by A Lansky, K Hochstatter; comments to author 19.02.18; revised version received 02.03.18; accepted 09.03.18; published 09.05.18

Please cite as:

Ti L, Parent S, Socías ME

Integrated Models of Care for People Living with Hepatitis C Virus and a Substance Use Disorder: Protocol for a Systematic Review JMIR Res Protoc 2018;7(5):e122

URL: http://www.researchprotocols.org/2018/5/e122/

doi: $10.2196 /$ resprot.9532

PMID: 29743153

CLianping Ti, Stephanie Parent, María Eugenia Socías. Originally published in JMIR Research Protocols (http://www.researchprotocols.org), 09.05.2018. This is an open-access article distributed under the terms of the Creative Commons Attribution License (https://creativecommons.org/licenses/by/4.0/), which permits unrestricted use, distribution, and reproduction in any medium, provided the original work, first published in JMIR Research Protocols, is properly cited. The complete bibliographic information, a link to the original publication on http://www.researchprotocols.org, as well as this copyright and license information must be included. 